\title{
Mutagenic Effectiveness and Efficiency of Gamma Rays, Ethyl Methane Sulphonate and their Combination Treatments in Chickpea (Cicer arietinum $\mathbf{L}$. )
}

\author{
Kamal Dev Sharma ${ }^{1 *}$, Gopal Katna ${ }^{2}$, Neha Sharma ${ }^{2}$, Ruby Nag ${ }^{1}$, Bipan Kumar Sharma ${ }^{3}$ \\ and Archana Joshi Saha ${ }^{4}$
}
${ }^{1}$ Department of Agricultural Biotechnology, ${ }^{2}$ Department of Crop Improvement, CSK HP Agricultural University, Palampur - 176062, Himachal Pradesh, India
${ }^{3}$ CSK HPKV Research Sub Station, Akrot, - 177211, Himachal Pradesh, India
${ }^{4}$ Nuclear Agriculture and Biotechnology Division, Bhabha Atomic Research Centre, Mumbai - 400085, Maharashtra, India

*Corresponding author

\section{A B S T R A C T}

\section{Keywords}

EMS, Gamma rays, Effectiveness,

Efficiency, Induced mutations, Chickpea

Article Info

Accepted:

07 October 2018

Available Online:

10 November 2018
A systematic and comparative study on mutagenic ability of different doses of ethyl methane sulphonate (EMS, an alkylating agent), gamma rays (an ionizing radiation) and EMS + gamma rays was carried out in a well-adapted desi chickpea variety HPG17. All mutagenic treatments were effective in inducing genetic variability. A proportional decrease in germination of mutagen treated seeds as well as subsequent plant survival was observed with increase in mutagen dose. Not only higher doses but combined treatments having low doses of EMS + gamma rays also reduced seed germination and plant survival with highest reduction in seed germination at $200 \mathrm{~Gy}+0.05 \%$ EMS and in plant survival at 150 Gy $+0.05 \%$. EMS appears to be better than gamma rays in induction of macromutations as maximum frequency of macromutants was at EMS $(0.10 \%)$. Mutagenic effectiveness and efficiency was also studied to identify the most effective mutagen treatment. Overall EMS was more effective than the gamma rays and combination treatments as maximum effectiveness was observed at $0.05 \%$ and $0.10 \%$ EMS, respectively. The $300 \mathrm{~Gy}+0.05 \%$ EMS had the highest mutagenic efficiency.

\section{Introduction}

In breeding programmes, creation of genetic variability is always the first step unless variation pre-exists. In the words of Altman (1999) "the release of new improved genotypes of classical breeding is now too slow to cope up with the demands and is considerably limited by the lack of natural genes that can be introgressed by genetic crosses". Consequently, mutation breeding has become an increasingly popular and efficient mean to create genetic variability and supplementing existing germplasm for cultivar 
improvement. In some cases undesirable mutants have been combined with favourable ideotype for breeding purpose (Stubbe, 1959).

Among pulses, chickpea (Cicer arietinum L.) is one of the most widely cultivated legume crop ranking second in area and third in production in the world with about 13.98 million hectare area and production of about 13.73 million tonnes in over 50 countries (FAO, 2017). Being a rich and cheap source of protein, chickpea helps to improve the nutritional quality of human diet and thus, plays a crucial role in food security in developing countries. Average global chickpea yield is far below its presumed potential and conventional breeding has not been able to increase the productivity as per its potential. This stagnation can be attributed to lack of sufficient variability for yield and its component traits, probably due to its monophyletic descendence from Cicer reticulatum and consequent vulnerability to biotic and abiotic stresses. Apprehensions regarding adaptability of available germplasm and association of linkage drag in wide hybrids coupled with arduous hybridization (Upadhyaya, 2015) make chickpea a potential crop for improvement through mutagenesis. Before starting any mutation breeding programme, knowledge of relative biological effectiveness and efficiency of various mutagens and their selection is essential to recover high frequency of desirable mutants (Smith, 1972). Mutagenic effectiveness is a measure of the frequency of mutations induced by unit dose of a mutagen, whereas mutagenic efficiency gives an idea of the proportion of mutations in relation to other associated undesirable biological effects such as gross chromosomal aberrations, lethality and sterility induced by the mutagen (Konzak et al., 1965). It is not necessary that an effective mutagen is also an efficient one (Gaikward and Kothekar, 2004). Synergistic and antagonistic effects may occur when various physical and chemical mutagens are used in combination. In the present study we report the comparative potential of EMS, gamma rays and combination doses of EMS + gamma rays for mutagenesis.

\section{Materials and Methods}

The dry seeds of HPG-17, a well-adapted desi chickpea variety in Himachal Pradesh were treated with gamma rays $(50 \mathrm{~Gy}, 100 \mathrm{~Gy}, 150$ Gy, 200 Gy, 300 Gy and 400 Gy), EMS $(0.05 \%, 0.10 \%$ and $0.15 \%)$ and all possible combinations of gamma rays $(150 \mathrm{~Gy}, 200 \mathrm{~Gy}$ and $300 \mathrm{~Gy})$ and EMS $(0.05 \%, 0.10 \%$ and $0.15 \%$ ). In each gamma rays + EMS treatment, 150 seeds were used whereas the number of seeds was 245 to 1014 for gamma rays treatments. Gamma irradiation was carried out in gamma chamber ${ }^{60} \mathrm{Co}$ gamma cell at Bhabha Atomic Research Centre (BARC), Mumbai. For treatment with EMS, seeds were first pre-soaked in distilled water for 14 hours at room temperature followed by immersion in freshly prepared EMS solution $(0.05 \%, 0.10 \%$ and $0.15 \%, w / v)$ for three hours in a shaker. The treated seeds were washed for three hours to terminate the residual effect of the mutagenic chemical and were sown immediately after the treatment. For treatment with both gamma rays and EMS, the seeds were first irradiated with gamma rays followed by EMS treatment. The seeds were sown in $2 \mathrm{~m}$ rows with spacing of $30 \mathrm{~cm}$ between rows and $10 \mathrm{~cm}$ between plants. The parent HPG-17 was used as control. For $\mathrm{M}_{1}$ generation, observations were recorded on per cent germination and per cent survival till maturity for each dose to calculate percentage reduction in seed germination and plant survival over control as per given formula:

$P=\left[1-\frac{S G \%_{t}}{S G \%}{ }_{n t}\right] \times 100$ 
$P=\left[1-\frac{P S \%_{t}}{P S \%_{n t}}\right] \times 100$

Where,

$\mathrm{P}=$ per cent population reduction over control

$\mathrm{SG} \%_{\mathrm{t}}=$ per cent seed germination in treatment $\mathrm{SG} \%_{\mathrm{nt}}=$ per cent seed germination in control $\mathrm{PS} \%_{\mathrm{t}}=$ per cent plant survival in treatment $\mathrm{PS} \%_{\mathrm{nt}}=$ per cent plant survival in control

$M_{2}$ seed from $M_{1}$ plants was harvested in April 2014 as single plant harvests and planted in the field in October 2014 as plant to row progenies with row of $2 \mathrm{~m}$ and spacing of $30 \mathrm{x}$ $10 \mathrm{~cm}$ (row to row $x$ plant to plant). Seeds harvested from individual $\mathrm{M}_{1}$ plant in each dose/treatment were sown as an $\mathbf{M}_{2}$ family. The respective control and treatment progenies were screened several times for morphological mutations throughout the crop duration. Mutation frequency was calculated as percentage of mutated $\mathrm{M}_{2}$ progenies in each treatment. Mutation frequency was used to calculate the mutagenic effectiveness and efficiency by using the formula suggested by Konzak et al., (1965).

Effectiveness of the

\section{$\mathrm{M}_{\mathrm{f}}$}

Chemical mutagen $=$

$$
\text { conc. * time }
$$

\section{$\mathrm{M}_{\mathrm{f}}$}

Effectiveness of the

Physical mutagen $=$

$\mathrm{kR}$

Effectiveness of combination of

\section{$\mathrm{M}_{\mathrm{f}}$}

Physical and chemical mutagen $=$

$$
\text { conc. } * \text { time } * \mathrm{kR}
$$

Efficiency of the chemical mutagen $=\frac{\mathrm{M}_{\mathrm{f}}}{-----}$
Where,

$\mathrm{M}_{\mathrm{f}}=$ mutation frequency (plant basis)

conc. $=$ concentration of EMS in $\mathrm{mM}(0.05 \%$

$=4.027 \mathrm{mM}, 0.1 \%=8.054 \mathrm{mM}, 0.15 \%=$ $12.081 \mathrm{mM})$

$\mathrm{kR}=$ gamma rays dose in $\mathrm{kR}(1 \mathrm{kR}=\mathrm{GY} / 10)$

$\% \mathrm{BI}=$ per cent biological damage

To evaluate the effect of combination treatments on mutation frequency the data were analyzed using the formula adopted by Doll and Sandfaer (1969): $(a)+(b)=1 / k(a+$ $b$ ), where $a$ and $b$ stand for two treatments and $\mathrm{k}$ is a hypothetical interaction coefficient. The value of $k$ should be one if the interaction is additive. Any deviation from this value should show synergistic or less than additive effects.

\section{Results and Discussion}

Reduction in germination of $\mathrm{M}_{1}$ seed was observed both in the individual as well as the combination treatments of mutagens (Table 1). The germination of seed treated with EMS varied from $39.33 \%$ to $46.00 \%$ depending upon the mutagen dose whereas for combination treatments the germination was $38.0 \%$ to $58.67 \%$ as compared to $76.67 \%$ in control (Table 1). The germination of seed treated with gamma rays ranged from $40.30 \%$ (400 Gy) to $78.08 \%$ (50 Gy) as compared to $80.90 \%$ in control (Table 1). The germination inhibition was dose dependent and a gradual decrease in germination over increase in the concentration/dose of mutagen was observed for gamma rays as well as EMS. Even, the lowest dose of EMS $(0.05 \%)$ was inhibitory (40.0\% inhibition) for chickpea germination. At $0.15 \%$ EMS, the germination inhibition was $48.70 \%$. Compared to EMS, gamma rays were less inhibitory to germination at low doses e.g. 50 Gy (3.49\% inhibition) and 100 
Gy (11.58\% inhibition), however, at a higher doses (200-400 Gy) germination inhibition (40.64\% at $200 \mathrm{~Gy}, 50.19 \%$ at $400 \mathrm{~Gy}$ ) was comparable to EMS doses (Table 1). Similar to germination, the mutagen treatments also affected the survival of germinated seedlings. The pattern of plant survival was similar to seed germination with less survival in case of EMS (69.45\% to $73.32 \%$ ) and more survival for gamma rays $(72.65 \%$ to $92.22 \%$ ) (Table 1). In case of combination treatments survival did not show a specific pattern $(99.72 \%$ at 300 $\mathrm{Gy}+0.05 \%$ EMS to $54.45 \%$ at $150 \mathrm{~Gy}+$ $0.05 \%$ EMS) whereas for gamma rays, the survival was dose dependent showing a gradual decrease over increase in dose of mutagen $199.22 \%$ at $150 \mathrm{~Gy}, 72.65 \%$ at 400 Gy). All EMS doses led to high reduction in survival over control (26.68\% to $30.55 \%)$. At higher doses of gamma rays, per cent reduction in survival ranged from 7.78 (100 Gy) to 27.35 (400 Gy) whereas for combination treatments, reduction in survival over control varied from $0.28 \%$ to $45.55 \%$. Comparison of EMS and gamma rays revealed that germination as well as survival was less in case of EMS as compared to gamma rays.

Decrease in germination over increase in dose of mutagens (EMS or gamma rays) was also observed by Giri (2014) in pigeonpea and Wani (2009) in chickpea. Similar to our observations, Wani (2009) also reported increase in lethality in some combination treatments (EMS + gamma rays). No dose dependent trend of increase or decrease in the mutation frequency, mutagenic effectiveness and mutagenic efficiency was observed (Table 1). Maximum mutation frequency was at $0.10 \%$ EMS $(0.605 \%)$ followed by at $0.05 \%$ EMS $(0.360 \%)$ with a minimum of $0.02 \%$ at $300 \mathrm{~Gy}$. Overall, the gamma rays had least mutagenic frequencies $(0.02 \%$ at 300 Gy to $0.120 \%$ at $200 \mathrm{~Gy}$ ), the EMS had highest mutation frequencies $(0.145 \%$ at $0.15 \%$ EMS to $0.605 \%$ at $0.10 \%$ EMS) whereas the mutation frequencies were moderate for the combination treatments with a maximum of $0.344 \%$ at $300 \mathrm{~Gy}+0.05 \%$ EMS. The most effective mutagen for chickpea was EMS with highest values of mutagenic effectiveness i.e. 0.0298 at $0.05 \%$ EMS and 0.025 at $0.10 \%$ EMS while the least effective was $300 \mathrm{~Gy}+$ 0.10 EMS with mutagenic effectiveness of 0.0001 . The effectiveness of lower doses of gamma rays $(0.0062$ at $150 \mathrm{~Gy}$ and 0.0060 at $200 \mathrm{~Gy})$ was more than higher doses $(0.0007$ at $300 \mathrm{~Gy}$ and 0.0006 at $400 \mathrm{~Gy}$ ). The gamma rays and combination treatments were not as effective as EMS alone. The $300 \mathrm{~Gy}+0.05 \%$ EMS gave the maximum efficiency (1.228) followed by $150 \mathrm{~Gy}+0.15 \%$ EMS (0.097) while minimum was observed in $400 \mathrm{~Gy}$ (0.0009). These results are in line with the results obtained by More and Borkar (2016) in Phaseolus vulgaris and Kharkwal (1998) in chickpea where EMS was found to be more effective than EMS + gamma rays. For combination treatments (EMS + gamma rays), results contrary to those obtained in the present study were reported by Wani (2009) and Kamble and Paril (2014) who testified combination treatments to be more effective in chickpea.

EMS and gamma rays have been used extensively in inducing variability and their comparative effects have been explored (Pathania and Sood, 2007; Bhat et al., 2011; Shah et al., 2011). Exploration and exploitation of two mutagens acting together has also been studied since long e.g. combination of gamma rays and ethylene imine in barley (Valeva, 1965), thermal neutrons and diethyl sulphate in rice (Rao and Ayengar, 1964) and X-rays and EMS in barley (Favret, 1963). The superiority of chemical mutagen over physical mutagen as observed in our study has also been demonstrated by Patial et al., (2015) in ricebean, Kharkwal (1998) in chickpea, Girija and Dhanavel (2009) in cowpea. 
Table.1 Effectiveness and efficiency of gamma rays, EMS and their combination treatments in $\mathrm{M}_{2}$ generation of Chickpea variety HPG-17

\begin{tabular}{|c|c|c|c|c|c|c|c|c|c|c|c|}
\hline Treatment & $\begin{array}{c}\text { Number of } \\
\text { seeds } \\
\text { treated }\end{array}$ & $\begin{array}{c}\text { Seed } \\
\text { germinati } \\
\text { on in } M_{1}\end{array}$ & $\begin{array}{l}\text { Per cent } \\
\text { germinati } \\
\text { on in } \mathbf{M}_{1}\end{array}$ & $\begin{array}{c}\text { Correcte } \\
\text { d } \\
\text { germinat } \\
\text { ion } \%\end{array}$ & $\begin{array}{l}\% \\
\text { reduction in } \\
\text { germination } \\
\text { over control }\end{array}$ & $\begin{array}{c}\text { Plant } \\
\text { survival } \\
\text { in } \mathbf{M}_{1}\end{array}$ & $\begin{array}{c}\text { Relative per } \\
\text { cent plant } \\
\text { survival in } \\
\mathbf{M}_{1}\end{array}$ & $\begin{array}{l}\text { Per cent } \\
\text { reduction in } \\
\text { survival } \\
\text { over control }\end{array}$ & $\begin{array}{l}\text { Mutation\# } \\
\text { frequency }\end{array}$ & $\begin{array}{l}\text { Mutagenic\# } \\
\text { effectiveness }\end{array}$ & $\begin{array}{l}\text { Mutagenic } \\
\text { efficiency }\end{array}$ \\
\hline $0.05 \%$ EMS & 150 & 69 & 46.00 & 60.00 & 40.00 & 45 & 69.45 & 30.55 & 0.360 & 0.0298 & 0.0118 \\
\hline $0.10 \%$ EMS & 150 & 61 & 40.67 & 53.05 & 46.95 & 42 & 73.32 & 26.68 & 0.605 & 0.0250 & 0.0227 \\
\hline $0.15 \%$ EMS & 150 & 59 & 39.33 & 51.30 & 48.70 & 39 & 70.39 & 29.61 & 0.145 & 0.0040 & 0.0049 \\
\hline $50 \mathrm{~Gy}$ & 552 & 431 & 78.08 & 96.51 & 3.49 & nd\#\# & - & - & - & - & - \\
\hline $100 \mathrm{~Gy}$ & 583 & 417 & 71.53 & 88.42 & 11.58 & nd\#\# & - & - & - & - & - \\
\hline $150 \mathrm{~Gy}$ & 245 & 168 & 68.57 & 84.76 & 15.24 & 141 & 92.22 & 7.78 & 0.090 & 0.0062 & 0.0116 \\
\hline $200 \mathrm{~Gy}$ & 1014 & 487 & 48.02 & 59.36 & 40.64 & 398 & 89.80 & 10.20 & 0.120 & 0.0060 & 0.0118 \\
\hline $300 \mathrm{~Gy}$ & 567 & 268 & 47.27 & 58.43 & 41.57 & 212 & 86.92 & 13.08 & 0.020 & 0.0007 & 0.0015 \\
\hline $400 \mathrm{~Gy}$ & 608 & 245 & 40.30 & 49.81 & 50.19 & 162 & 72.65 & 27.35 & 0.024 & 0.0006 & 0.0009 \\
\hline $\begin{array}{c}150 \mathrm{~Gy}+0.05 \% \\
\text { EMS }\end{array}$ & 150 & 88 & 58.67 & 76.52 & 23.48 & 45 & 54.45 & 45.55 & 0.192 & 0.0011 & 0.0042 \\
\hline $\begin{array}{c}150 \mathrm{~Gy}+0.10 \% \\
\text { EMS }\end{array}$ & 150 & 77 & 51.33 & 66.95 & 33.05 & 58 & 80.21 & 19.79 & 0.264 & 0.0007 & 0.0133 \\
\hline $\begin{array}{c}150 \mathrm{~Gy}+0.15 \% \\
\text { EMS } \\
\end{array}$ & 150 & 75 & 50.00 & 65.21 & 34.79 & 68 & 96.55 & 3.45 & 0.337 & 0.0006 & 0.0977 \\
\hline $\begin{array}{c}200 \mathrm{~Gy}+0.05 \% \\
\text { EMS }\end{array}$ & 150 & 57 & 38.00 & 49.56 & 50.44 & 43 & 80.33 & 19.67 & 0.172 & 0.0007 & 0.0087 \\
\hline $\begin{array}{c}200 \mathrm{~Gy}+0.10 \% \\
\text { EMS } \\
\end{array}$ & 150 & 60 & 40.00 & 52.17 & 47.83 & 40 & 70.99 & 29.01 & 0.136 & 0.0003 & 0.0047 \\
\hline $\begin{array}{c}200 \mathrm{~Gy}+0.15 \% \\
\text { EMS }\end{array}$ & 150 & 66 & 44.00 & 57.39 & 42.61 & 35 & 56.47 & 43.53 & 0.207 & 0.0003 & 0.0048 \\
\hline $\begin{array}{c}300 \mathrm{~Gy}+0.05 \% \\
\text { EMS }\end{array}$ & 150 & 63 & 42.00 & 54.78 & 45.22 & 59 & 99.72 & 0.28 & 0.344 & 0.0009 & 1.2286 \\
\hline $\begin{array}{c}300 \mathrm{~Gy}+0.10 \% \\
\text { EMS }\end{array}$ & 150 & 68 & 45.33 & 59.12 & 40.88 & 52 & 81.43 & 18.57 & 0.071 & 0.0001 & 0.0038 \\
\hline $\begin{array}{c}300 \mathrm{~Gy}+0.15 \% \\
\text { EMS } \\
\end{array}$ & 150 & 70 & 46.67 & 60.87 & 39.13 & 64 & 97.36 & 2.64 & 0.200 & 0.0002 & 0.0758 \\
\hline Control $^{*}$ & 150 & 115 & 76.67 & 100.00 & & 108 & 100.00 & - & - & - & - \\
\hline Control $^{*}$ & 1100 & 890 & 80.90 & 100.00 & & 810 & 100.00 & - & - & - & - \\
\hline
\end{tabular}

\#Calculated using $\mathrm{mM}$ values of EMS e.g. $0.1 \%=8.054 \mathrm{mM}$, \#\#not determined, *Control for EMS and gamma rays + EMS treatments, ** Control for gamma ray treatments 
Contrary to our study, there are reports showing that combination treatments were more effective and efficient in chickpea (Wani, 2009; Kamble and Paril, 2014). However, both the studies i.e., Wani (2009) and Kamble and Paril (2014) used higher EMS concentrations $(0.10,0.20,0.30$ and $0.40 \%$ ) than those used in the present study $(0.05,0.10$ and $0.15 \%)$.

The present study established that the chemical mutagen EMS was superior to gamma rays in reducing germination of treated chickpea seeds and subsequent survival of plants. Some of the combination treatments (EMS + gamma rays) were more effective than EMS for reduction in germination and plant survival. Similarly, EMS had higher mutation frequency and mutagenic effectiveness as compared to either gamma rays or EMS + gamma rays. In contrast to this, EMS + gamma rays were more efficient in mutation induction than EMS or gamma rays.

\section{Acknowledgements}

The authors acknowledge financial grant (Sanction Number: 35/14/22/2014-BRNS) received from BRNS, BARC, Government of India

\section{References}

Altman, A. 1999. Plant biotechnology in the $21^{\text {st }}$ century: the challenges ahead. Electronic Journal of Biotechnology 2(2):51-55.

Barshile, J.D., Auti, S.G., Dalve, S.C. and Apparao, B.J. 2006. Mutagenic sensitivity studies in chickpea employing SA, EMS and gamma rays. Indian Journal of Pulse Research 19: 43-46.

Bhat, M.U.D., Khan, S. and Kozgar, M.I. 2011. Studies on induced mutations in chickpea (Cicer arietinum L.) I. Responses of the mutagenic treatments in $\mathrm{M}_{1}$ biological parameters. Electronic Journal of Plant Breeding, 2: 422-424.

Doll, H. and Sandfaer, J. 1969. Mutagenic effect of gamma rays, diethyl sulphate, EMS and various combinations of gamma rays and chemicals. In. Induced Mutation in plants. Proceeding of Symposium, International Atomic energy, Pullman. Pp. 195-205.

FAO. 2017. Food and Agricultural Organization. FAO Website (http://faostat.org/).

Favret, E.A. 1963. Genetic effects of single and combined treatment of ionizing radiation and EMS on barley seeds. Proceedings of International Barley Genetics, Wageningen. Pp. 68-81.

Gaikwad, N.B. and Kothekar, V.S. 2004. Mutagenic effectiveness and efficiency of ethyl methane sulphonate and sodium azide in lentil. Indian Journal of Genetics and Plant Breeding 64(1): 73:74.

Giri, S.P. 2014. Studies of mutagenic sensitivity in pigeonpea [Cajanus cajan (L.) Mill sp.]. Bioscience Discovery 5(2): 227-229.

Girija, M. and Dhanavel, D. 2009. Mutagenic effectiveness and efficiency of gamma rays, ethyl methane sulphone and their combined treatments in cowpea (Vigna unguiculata L. Walp). Global Journal of Molecular Sciences 4(2):68-75.

Kamble, G.C. and Paril, A.S. 2014. Comparative mutagenicity of EMS and gamma radiation in wild chickpea. International Journal of Science, Environment and Technology 3: 166180.

Kharkwal, M.C. 1998. Induced mutations in chickpea (Cicer arietinum L.). I. Comparative mutagenic effectiveness and efficiency of physical and chemical 
mutagens. Indian Journal of Genetics and Plant Breeding 58: 159-167.

Konzak, C.F., Nilan, R.A., Wanger, J. and Foster, R.J. 1965. Efficient chemical mutagenesis. In the use of induced mutations in plant breeding. Radiation Botany 5: 49-70.

Lamprecht, H. 1960. Uber Blattfarben von Phanerogamen. Klassifikation, Terminologie und Gensymbole von chlorophyll und anderen Farbmutanten. Agri Hortique Genetica 18: 135-168.

More, A.D. and Borkar, A.T. 2016. Mutagenic effectiveness and efficiency of gamma rays and EMS in Phaseolus vulgaris L. International Journal of Current Microbiology and Applied Sciences 5(10): 544-554.

Pathania, A. and Sood, B.C. 2007. Comparative effectiveness and efficiency of physical and chemical mutagens in chickpea (Cicer arietinum L.). Legume Research 30: 186-191.

Patial, M., Thakur, S.R. and Singh, K.P. 2015. Comparative mutagenic effectiveness and efficiency of physical and chemical mutagen and induced variability in ricebean (Vigna umbellate Thunb, Ohwi and Ohashi). Legume Research 38(1): 30-36.

Rao, N.S. and Gopal, A.A.R. 1964. Combined effect of thermal neutrons and diethyl sulphate on mutation frequency and spectrum in rice. In Biological Effects of Neutron and Proton Irradiations, Vol.
1, STI/PUB/80, International Atomic Energy Agency, Vienna pp 383-391.

Shah, T.M., Atta, B.M., Mirza, J.I. and Haq, M.A. 2011. Induced genetic variability in chickpea (Cicer arietinum L.) III. Frequency of morphological mutations. Pakistan Journal of Botany 43: 2039 2043.

Smith, H.H. 1972. Comparative genetic effects of different physical mutagens in higher plants. In: Joint FAO/IAEA Division of Atomic Energy in Food and Agriculture, ed. Induced Mutations and Plant Breeding Improvement IAEA, Vienna pp: 75-93.

Stubble, H. 1959. Some results and problems of theoretical and applied mutation research. Indian Journal of Plant breeding and Genetics 19(1): 13-29.

Upadhyaya, H.D. 2015. Enhancing core collections for enhanced use of germplasm in crop improvement. Ekin Journal of Crop Breeding and Genetics 1: 1-12.

Valeva, S.A. 1965. Effects of combined treatments of mutagens. Symposium on experimental mutagenesis in animals, plants and microorganisms, Moscow 2: 46.

Wani, A.A. 2009. Mutagenic effectiveness and efficiency of gamma rays, ethyl methane sulphonate and their combination treatments in chickpea (Cicer arietinum L.). Asian Journal of Plant Science 8: 318-321.

\section{How to cite this article:}

Kamal Dev Sharma, Gopal Katna, Neha Sharma, Ruby Nag, Bipan Kumar Sharma and Archana Joshi Saha. 2018. Mutagenic Effectiveness and Efficiency of Gamma Rays, Ethyl Methane Sulphonate and their Combination Treatments in Chickpea (Cicer arietinum L.). Int.J.Curr.Microbiol.App.Sci. 7(11): 509-515. doi: https://doi.org/10.20546/ijcmas.2018.711.061 